\title{
Uji Tuberkulin pada Bayi BBLR yang Mendapat BCG Segera Setelah Lahir dan yang Menunggu Berat Badan $\geq 2500$ Gram
}

\author{
Darfioes Basir, Finny FitryYani, Triyanto \\ Divisi Respirologi, Bagian Ilmu Kesehatan Anak Fakultas Kedokteran Universitas Andalas/ RS Dr. M \\ Djamil Padang.
}

\begin{abstract}
Latar belakang. Vaksinasi BCG pada bayi BBLR (berat badan lahir rendah) belum menjadi kesepakatan dalam program imunisasi nasional di Indonesia. Beberapa penelitian sebelumnya melaporkan efektifitas BCG pada bayi BBLR/preterm dengan menggunakan uji tuberkulin 27\% sampai $83 \%$.

Tujuan. Menilai efektifitas BCG pada bayi BBLR dengan uji tuberkulin di RS.Dr. M. Djamil Padang Metode. Penelitian bersifat randomized clinical trial pada bayi BBLR 2000gram-<2500gram yang lahir dan/atau dirawat di Sub Bagian Perinatologi Bagian Ilmu Kesehatan Anak, dari bulan Juni sampai November 2006. Setiap subjek yang masuk penelitian, diberikan informed concent, dikelompokkan dalam 2 kelompok dengan simple random sampling. Kelompok 1 diberikan BCG segera setelah lahir, maksimal 3 hari. Sedangkan kelompok 2 ditunda pemberian BCG sampai berat badan $\geq 2500$ gram. Kedua kelompok di dilakukan uji tuberkulin dan pemeriksaan parut 12 minggu setelah vaksinasi BCG serta mengisi kuisioner. Data penelitian diolah dengan SPSS 13.0 for Windows dan di analisis dengan $t$-test, $\mathrm{X}^{2}$ test (kai-kuadrat) dan uji mutlak Fischer dengan $\alpha=0,05$.

Hasil. Selama 6 bulan, telah lahir dan/atau dirawat 107 bayi BBLR berat 2000gram - <2500gram. 60 bayi memenuhi kriteria inklusi dan 44 bayi menyelesaikan penelitian. Rerata diameter indurasi tuberkulin pada kelompok $14,91 \pm 2884 \mathrm{~mm}$ dan kelompok 2 5,41 $\pm 2,085 \mathrm{~mm}$ yang secara statistik tidak berbeda bermakna dengan $\mathrm{p}=0,510$. Nilai konversi uji tuberkulin pada kelompok 1 sebesar 63,6\% dan kelompok 2 $81,8 \%$ tidak menunjukan perbedaan $\mathrm{p}=0,310$.

Kesimpulan. Vaksinasi BCG bayi BBLR berat 2000gram-<2500gram segera setelah lahir memberikan efektifitas sama dengan yang ditunda. (Sari Pediatri 2007; 9(4):293-8).
\end{abstract}

Kata kunci: BCG, bayi BBLR, uji tuberkulin

\footnotetext{
Alamat korespondensi

Dr. Finny Fitry Yani, SpA Divisi Respirologi Departemen IKA FK Universitas Andalas Padang
}

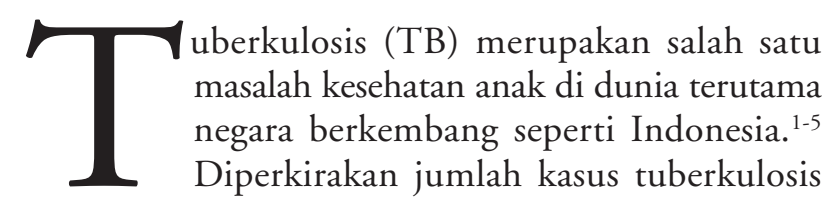


anak per tahun 5\% sampai $6 \%$ dari total kasus tuberkulosis. ${ }^{5}$ Jumlah anak yang terinfeksi tuberkulosis menyebabkan angka kematian meningkat, kecacatan, biaya dan waktu pengobatan. ${ }^{6}$ Pencegahan tuberkulosis merupakan salah satu upaya penting yang harus dilakukan dengan pengendalian berbagai faktor risiko infeksi tuberkulosis. ${ }^{5-7}$

Risiko tuberkulosis pada anak dapat dikurangi dengan pemberian vaksinasi BCG. ${ }^{5}$ Pemberian vaksinasi BCG pada bayi baru lahir sampai usia 2 bulan sudah merupakan kesepakatan dalam program imunisasi nasional di Indonesia, dengan cakupan imunisasi yang terus meningkat setiap tahunnya. ${ }^{8}$ Data dari Dinas Kesehatan tingkat I Sumatera Barat menyatakan cakupan imunisasi BCG tahun 2004 adalah 99,5\% dan di kota Padang 100\%. Sampai saat ini tidak ada prosedur tetap dalam pemberian vaksinasi BCG pada bayi BBLR yang merupakan 8\%-14\% dari semua neonatus. ${ }^{9}$

Bayi BBLR secara imunokompeten kurang memberikan respons terhadap antigen $\mathrm{BCG},{ }^{10}$ tetapi beberapa penelitian yang sudah dilakukan oleh Sudhan dkk tahun 1995-1997, ternyata memperlihatkan hasil seroconvertion yang sama antara bayi preterm yang diberikan vaksinasi BCG langsung saat lahir dengan pemberian vaksinasi BCG yang ditunda sampai umur kronologis bayi cukup bulan (38-40 minggu). ${ }^{9}$

Keberhasilan imunisasi ditentukan oleh beberapa faktor, yaitu status imun pejamu, faktor genetik pejamu serta kualitas dan kuantitas vaksin. ${ }^{8,11}$ Vaksinasi BCG pada bayi preterm, dapat berhasil baik apabila faktorfaktor pendukung tersebut di atas terpenuhi. Seperti dibuktikan penelitian sebelumnya yang melaporkan, tidak terdapat perbedaan respon seroconvertion antara bayi preterm dibandingkan dengan bayi cukup bulan setelah vaksinasi BCG. ${ }^{9}$

Penggunaan uji tuberkulin dalam menilai keberhasilan vaksinasi BCG telah dilakukan oleh beberapa peneliti. Diantaranya adalah Dawodu ${ }^{12}$ tahun 1985 yang melaporkan tidak ada perbedaan nilai konversi uji tuberkulin 12 bayi BBLR yang divaksinasi saat lahir, dan 8 bayi BBLR yang divaksinasi saat umur kronologis 38-40 minggu. Sudhan $\mathrm{dkk}^{9}$ tahun $1995-$ 1997 juga melakukan penelitian uji tuberkulin pada 61 bayi preterm dan didapatkan hasil vaksinasi BCG efektif dan aman pada bayi preterm. Penelitian Ferrera $\mathrm{dkk}^{13}$ pada bayi cukup bulan dan bayi berat lahir rendah yang divaksinasi BCG saat lahir, juga mendapatkan angka konversi tuberkulin $\pm 81,2 \%$.
Berdasarkan hal-hal tersebut di atas penulis juga tertarik untuk melakukan penelitian uji tuberkulin pada bayi BBLR di RS M Djamil Padang.

\section{Metode}

Penelitian uji klinik acak (randomize clinical trial) dilakukan di Sub Bagian Perinatologi, Bagian Ilmu Kesehatan Anak RS Dr. M Djamil Padang dari bulan Juni sampai November 2006. Populasi penelitian adalah bayi yang lahir hidup di RS. Dr. M Djamil Padang dengan berat badan saat lahir 2000 gram sampai < 2500 gram antara bulan Juni sampai November 2006. Subjek minimal yang diperlukan 44 bayi, melalui simple random sampling subjek dibagi dalam 2 kelompok. Kelompok 1 diberikan vaksinasi BCG segera setelah lahir dan kelompok 2 vaksinasi BCG diberikan setelah berat badan $\geq 2500$ gram.

Kriteria inklusi adalah bayi-bayi dengan BBL 2000 gram sampai <2500 gram, usia kehamilan $<37$ minggu sedangkan untuk kontrol bayi BBL 2000 gram sampai $<2500$ gram yang ditunda pemberian vaksinasi BCG sampai berat badan mencapai $\geq 2500$ gram. Semua bayi mempunyai BBL yang sesuai dengan masa kehamilan (SMK) dan bersedia ikut dalam penelitian. Bayi yang sedang sakit, mendapat transfusi tukar, bayi kembar, mendapatkan pengobatan immunoglobulin, steroid, INH profilaksis, serta bayi (kecil masa kehamilan) tidak diikutkan dalam penelitian.

Timbangan bayi yang dipakai digital, merk SECA Vogel \& Halke Germany, model 7271321004 , no. 1727349990861. Vaksin BCG yang dipergunakan adalah vaksin BCG kering yang mengandung kuman hidup dari biakan Bacillus Calmette \& Guerin Institut Pasteur Paris No 1173P2 diproduksi oleh PT. Bio Farma Bandung. Tuberkulin yang dipakai adalah PPD RT 232 TU/ 0,1 ml diproduksi oleh Bio Farma Bandung dengan No. 650035 dan kadaluarsa pada Agustus 2008, tuberculin disposable syringe nomor $25 \mathrm{G}$, penggaris transparan, alkohol $70 \%$ dan kuisioner.

\section{Cara kerja}

Subjek penelitian adalah bayi BBLR yang dirawat di RS Dr. M Djamil Padang, baik yang lahir di rumah sakit tersebut maupun kiriman dari rumah sakit lain, 
klinik bersalin, dan praktek bidan. Orang tua bayi diberikan penjelasan tentang rencana penelitian kemudian mengisi informed consent. Setiap subjek bayi BBLR yang memenuhi kriteria inklusi dilakukan simple random dibagi dalam 2 kelompok. Kelompok 1 adalah bayi BBLR diberikan vaksinasi BCG segera setelah lahir maksimal hari ke 3. Kelompok 2 adalah bayi BBLR yang akan divaksinasi BCG saat mempunyai berat badan $\geq 2500$ gram dengan meminta orang tua membawa bayinya ke rumah sakit untuk vaksinasi BCG. Bila bayi tidak datang, maka petugas kesehatan yang ditunjuk dan dilatih cara pemberian vaksinasi BCG dan uji tuberkulin atau peneliti sendiri akan mengunjungi rumah bayi itu untuk pemberian vaksinasi BCG. Semua subjek setelah 12 minggu dari pemberian BCG dilakukan uji tuberkulin dengan PPD RT 23-2TU 0,1 ml intrakutan pada lengan kanan bawah bagian volar. Penyuntikan dilakukan oleh peneliti dan 2 orang perawat anak yang terlatih dan berpengalaman. Perawat tersebut sudah bekerja sebagai penyuntik tuberkulin selama 10-20 tahun di poliklinik anak RS M Djamil. Setelah 72 jam, dilakukan pembacaan hasil uji tuberkulin dan semua data dicatat oleh peneliti pada formulir/kuisioner yang disediakan.

Seluruh data dari kuisioner dicatat pada formulir yang ditentukan, dan diolah dengan program SPSS 13.0 for window, kemudian dianalisis dengan uji $t$ test, tes $\mathrm{X}^{2}$ (kai-kuadrat) dan uji mutlak Fischer dengan $\alpha=0,05$.

\section{Hasil}

Pengumpulan data dilakukan selama 6 bulan, dari bulan Juni 2006 sampai November 2006. Selama periode penelitian terdapat 107 bayi BBLR dengan berat badan berkisar 2000 gram sampai < 2500 gram yang lahir dan atau dirawat di Sub Bagian Perinatologi Ilmu Kesehatan anak RS Dr. M Jamil Padang

Diantara 60 bayi yang memenuhi kriteria inklusi, terdapat 16 bayi yang dikeluarkan dari penelitian karena orang tua dari 3 bayi tidak bersedia untuk dilakukan uji tuberkulin, 4 bayi mempunyai alamat rumah yang tidak benar atau tidak lengkap, 3 bayi pindah ke luar kota yang tidak mungkin dikunjungi dan 6 bayi jadwal uji tuberkulin dilakukan melewati batas waktu penelitian (6 bulan). Subjek yang dapat meneruskan penelitian 44 bayi yang terdiri dari 22 bayi pada kelompok 1 dan 22 pada kelompok 2 .

\section{Karakteristik sampel}

Pada Tabel 1 tertera tidak terdapat perbedaan bermakna antara kelompok 1 dan kelompok 2 dengan nilai $p$ $=0,350$ dan 0,402

\section{Parut BCG}

Parut BCG ditemukan pada 37/44 bayi (84,1\%). Apabila ditinjau berdasarkan pembagian kelompok 1

Tabel 1. Karakteristik subjek

\begin{tabular}{|c|c|c|c|c|c|c|c|c|c|}
\hline \multirow{2}{*}{ Karakteristik } & \multicolumn{3}{|c|}{ Kelompok $1^{*}$} & \multicolumn{5}{|c|}{ Kelompok $2^{* *}$} & \multirow{2}{*}{ nilai $\mathrm{P}$} \\
\hline & $\mathrm{N}$ & $\%$ & Rerata & SD & $\mathrm{n}$ & $\%$ & Rerata & SD & \\
\hline Jumlah subjek & 22 & 100 & & & 22 & 100 & & & \\
\hline \multicolumn{10}{|l|}{ Cara Lahir } \\
\hline Spontan & 16 & 72.7 & & & 17 & 77.3 & & & \\
\hline Tindakan/operasi & 6 & 27.3 & & & 5 & 22.7 & & & \\
\hline Jenis kelamin & & & & & & & & & $0,350^{\$}$ \\
\hline - laki-laki & 8 & 36.4 & & & 10 & 45.5 & & & \\
\hline - perempuan & 14 & 63.6 & & & 12 & 54.5 & & & \\
\hline Usia kehamilan (minggu) & & & 35 & 1,1 & & & 34,7 & 1,1 & \\
\hline Berat lahir (gram) & & & 2294 & 169,9 & & & 2240 & 171,9 & $0,402^{\#}$ \\
\hline Usia ibu (tahun) & & & 28,86 & 5,5 & & & 28,5 & 5,5 & \\
\hline \multicolumn{10}{|c|}{$\begin{array}{l}\$ \text { Analisis dengan } \mathrm{X}^{2}(\alpha=0,05) \\
\text { * Analisis dengan } t \text {-test (nilai kemaknaan }<0,05) \\
* \text { Kelompok } 1: \text { Bayi BBLR yang divaksinasi saat setelah lahir } \\
\text { ** Kelompok } 2: \text { Bayi BBLR ditunda vaksinasi sampai } \mathrm{BB} \geq 25\end{array}$} \\
\hline
\end{tabular}


dan 2 didapatkan hasil seperti tertera pada Gambar 1.

Gambar 1 memperlihatkan perbandingan hasil pemeriksaan parut BCG kelompok 1 dengan kelompok 2 yang secara statistik tidak menunjukkan perbedaan hasil yang bermakna dengan nilai $\mathrm{p}=0,680$

\section{Uji Tuberkulin}

Pada Tabel 2 tampak kedua kelompok tidak menunjukkan perbedaan bermakna, $\mathrm{p}=0,510$.

Gambar 2 menunjukkan hasil diameter indurasi uji tuberkulin berdasarkan variasi nilai pengukuran. Panjang rentang garis pada box plot kelompok 1 lebih besar dibandingkan kelompok 2 (lingkaran pada gambar boxplot).

Apabila hasil dari diameter indurasi uji tuberkulin dikelompokkan, maka akan didapatkan nilai seperti Gambar 3.

Gambar 3 memperlihatkan hasil diameter indurasi uji tuberkulin pada kedua kelompok yang dibagi kedalam 3 bagian. Terlihat bahwa proporsi terbesar terbagi pada kelompok diameter 4-6 $\mathrm{mm}$ diikuti kelompok 7-10 mm dan 0-3 mm. Namun hasil uji statistik menunjukkan tidak terdapat perbedaan yang bermakna antara kedua kelompok dengan nilai $\mathrm{p}=$ 0,432

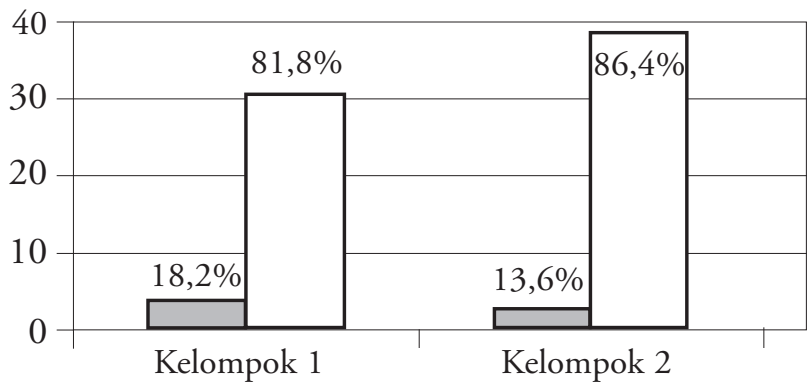

Negatif $\square$ Positif

Gambar 1. Proporsi parut BCG setelah pemberian vaksinasi BCG pada bayi BBLR

Tabel 2. Rerata diameter indurasi uji tuberkulin pada kedua kelompok

\begin{tabular}{lcccc}
\hline Kelompok & $\mathrm{n}$ & Rerata & SB & Nilai p $^{*}$ \\
\hline Kelompok 1 & 22 & 4,91 & 2,844 & \\
Kelompok 2 & 22 & 5,41 & 2,085 & 0,510 \\
\hline
\end{tabular}

*Analisis statistik t-test (nilai kemaknaan $<0,05$ )
Dari kedua kelompok yang dilakukan uji tuberkulin didapatkan 32/44 bayi (72,3\%) memperlihatkan reaksi uji tuberkulin positif. Bila dilihat berdasarkan masing-masing kelompok didapat sebagai berikut.

Tabel 3 menunjukkan bahwa konversi uji tuberkulin positif lebih banyak pada kelompok dengan pemberian vaksin yang ditunda sampai berat bayi $\geq 2500$ gram. Walaupun secara statistik temuan ini tidak menunjukkan hasil bermakna dengan $\mathrm{p}=0.310$

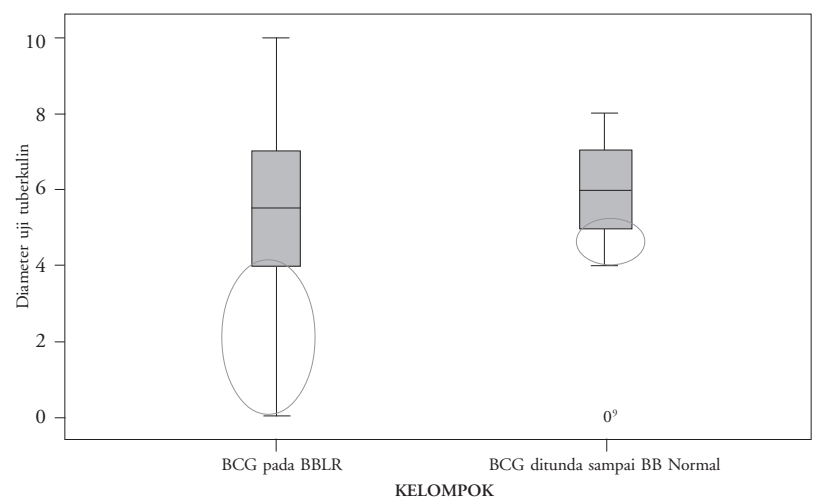

Gambar 2. Box plot diameter indurasi uji tuberkulin pada kedua kelompok penelitian

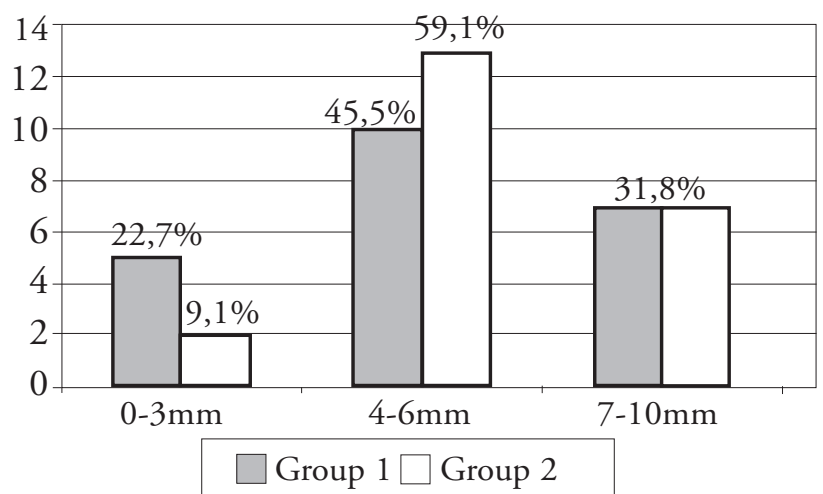

Gambar 3. Diameter indurasi uji tuberkulin pada kedua kelompok penelitian

Tabel 3. Hasil uji tuberkulin setelah pemberian vaksin BCG pada bayi BBLR

\begin{tabular}{lcccc}
\hline \multirow{2}{*}{ Uji tuberkulin } & \multicolumn{2}{c}{ Kelompok 1 } & \multicolumn{2}{c}{ Kelompok 2 } \\
\cline { 2 - 5 } & $\mathrm{n}$ & $\%$ & $\mathrm{n}$ & $\%$ \\
\hline Negatif & 8 & 36,4 & 4 & 18,2 \\
Positif & 14 & 63,6 & 18 & 81,8 \\
\hline Jumlah subjek & 22 & 100 & 22 & 100 \\
\hline
\end{tabular}

Analisis statistik dengan Fisher's Exact Test (2 tailed) 


\section{Efek samping BCG}

Efek samping penyuntikkan vaksin BCG dan uji tuberkulin berupa reaksi alergi, limfadenitis, abses dan lain-lain tidak ditemukan pada semua subjek penelitian.

\section{Diskusi}

Parut BCG ditemukan positif pada $81,8 \%$ bayi BBLR yang divaksinasi segera setelah lahir, sedangkan bayi BBLR yang ditunda positif $86,4 \%$. Secara statistik tidak terdapat perbedaan bermakna antara kedua group dengan $\mathrm{p}=0,680$. Dawodu $\mathrm{AH}^{12}$ meneliti uji tuberkulin pada BBLR, tidak mengevaluasi parut BCG. Sedaghatian dan Kardouni ${ }^{14}$ mengobservasi parut berukuran diameter $>3 \mathrm{~mm}$ terjadi pada 63,3\% dari 101 bayi yang divaksinasi BCG. Begitu juga parut BCG terdapat pada 55\% dari 36 bayi yang diteliti oleh Sedaghatian dkk, ${ }^{15}$ dan parut atau ulkus BCG yang diamati pada penelitian Sudhan $\mathrm{dkk}^{9}$ sebanyak 27 bayi preterm (90\%). Pembentukkan parut BCG yang rendah pada penelitian SedaghatianKardouni dan Tun KM dkk, ${ }^{14}$ dimungkinkan akibat kesalahan teknik yang muncul pada waktu pemberian/ penyuntikan vaksin BCG atau akibat perubahan bioavaibilitas dan potensi vaksin.

Rerata diameter indurasi tuberkulin pada penelitian ini pada kelompok 1 adalah $(4,91 \pm 2,88) \mathrm{mm}$ dan pada kelompok 2 sebesar $(5,41 \pm 2,08) \mathrm{mm}$, dan secara statistik tidak menunjukkan perbedaan. Hasil ini hampir sama dengan penelitian yang dilakukan Sudhan $\mathrm{dkk}^{9}$ yang mendapatkan $(5,27 \pm 1,8) \mathrm{mm}$ untuk bayi preterm yang segera di vaksinasi BCG dan $(5,26 \pm 1,6) \mathrm{mm}$ pada bayi preterm yang ditunda BCG sampai cukup bulan (3840 minggu) Namun masih dibawah bila dibandingkan dengan Ferreira $\mathrm{AA}^{13}$ yang mendapatkan rerata diameter indurasi tuberkulin pada bayi BBLR segera divaksinasi BCG segera setelah lahir $(9,5 \pm 5,1)$ mm dibandingkan $(9,6 \pm 5,0) \mathrm{mm}$ pada bayi BBLC (berat badan lahir cukup) sebagai kontrol. Sementara itu di Brazil Camargos P dkk ${ }^{16}(2002)$ melaporkan $(6,8 \pm 4,70) \mathrm{mm}$ untuk bayi preterm dan $(10,2 \pm 4,53) \mathrm{mm}$ bayi BBLC, terdapat perbedaan diameter indurasi yang cukup lebar antara kedua kelompok.

Sudah banyak penelitian tentang BCG pada neonatus dipublikasikan, namun masalah pemberian vaksinasi BCG pada bayi preterm atau bayi BBLR masih kontroversi. Penelitian sebelumnya melaporkan frekuensi indurasi $\geq 5 \mathrm{~mm}$ sampai $6 \mathrm{~mm}$ adalah Tun KM 27\%, Sedaghatian-Kardouni 31\%, ${ }^{14}$ SedaghatianHashem 67\%, ${ }^{15}$ Camargos ${ }^{16} 67,5 \%$, Sudhan ${ }^{9} 80 \%$, dan Dawodu $\mathrm{AH}^{12}$ 83\%. Variasi yang didapatkan pada penelitian-penelitian tersebut dimungkinkan akibat perbedaan metodologi, galur BCG, kriteria inklusi dan eksklusi, kesalahan dalam pengambilan sampel, kesalahan dalam pengelompokkan sampel, pabrik PPD yang dipergunakan dan penetapan cut-off point diameter reaksi tuberkulin.

Diameter indurasi hasil uji tuberkulin memperlihatkan tidak terdapat perbedaan antara bayi BBLR yang divaksinasi BCG segera setelah lahir $(63,6 \%)$ dengan bayi BBLR yang ditunda vaksinasinya sampai berat bayi mencapai $\geq 2500$ gram $(81,8 \%)$ dengan $\mathrm{p}=0,310(\mathrm{p}>0,05)$. Sedangkan Dawodu $\mathrm{AH}^{12}$ melaporkan angka konversi tuberkulin (indurasi $\geq 5 \mathrm{~mm}$ ) $83 \%$ dari 12 bayi preterm yang divaksinasi saat lahir dibandingkan $88 \%$ pada 8 bayi preterm yang divaksinasi saat 38-40 minggu. Tidak terdapat perbedaan bermakna antara kedua kelompok bayi tersebut. Dua penelitian yang dilakukan Sedaghatian ${ }^{14,15}$ tentang uji tuberkulin pada bayi preterm setelah vaksinasi BCG. Pada penelitian pertama memeriksa respon tuberkulin setelah pemberian vaksinasi BCG pada bayi preterm saat lahir, dilaporkan nilai konversi tuberkulin 20\%. Peneliti menyimpulkan vaksinasi rutin BCG pada bayi preterm tidak diindikasikan. Namun penelitian ini mempunyai kelemahan karena follow up kurang baik dan memasukkan bayi sakit serta KMK dalam subjek penelitiannya. Sedangkan pada penelitian kedua Sedaghatian $\mathrm{dkk}^{14,15}$ membandingkan uji tuberkulin pada 36 bayi preterm yang divaksinasi BCG segera saat lahir dengan 16 bayi preterm yang divaksinasi saat usia 40 minggu dan 20 bayi cukup bulan. Didapatkan konversi tuberkulin adalah 33\% versus $25 \%$ versus $25 \%$, secara statistik tidak ada perbedaan bermakna antara ke 3 kelompok bayi $(p>0,4)$, dari analisis multivariat didapatkan hubungan bermakna antara berat lahir dengan reaksi uji tuberkulin. Sehingga peneliti tidak menganjurkan vaksinasi BCG secara rutin pada bayi preterm <33 minggu, sampai penelitian berikutnya dilakukan. ${ }^{15}$

Penelitian Sudhan dkk' (1997) mendapatkan hasil tidak terdapat perbedaan konversi tuberkulin antara bayi preterm yang divaksinasi BCG segera saat lahir (80\%) dengan yang ditunda sampai cukup bulan (3840 minggu) (80,7\%). Sedangkan penelitian terbaru yang dilakukan oleh Camargos $\mathrm{P} \mathrm{dkk}^{16}$ di Brazil mendapatkan hasil konversi tuberkulin pada bayi 
BBLR 2000 gram-2499 gram yang divaksinasi BCG segera saat lahir $67,5 \%$ dan vaksinasi pada bayi-bayi cukup bulan $87,7 \%$. Terdapat $20,2 \%$ perbedaan antara kedua kelompok $(p=0,02)$. Tetapi peneliti pada kesimpulannya tetap menganjurkan vaksinasi BCG pada bayi BBLR saat pulang dari perawatan di Unit Neonatal dengan alasan untuk mengurangi angka kesakitan dan kematian pada bayi berisiko infeksi tuberkulosis dan untuk meningkatkan angka cakupan imunisasi BCG, khususnya di negara dengan angka prevalensi TB tinggi.

Hubungan antara perlindungan yang dihasilkan oleh vaksinasi BCG dengan respon uji tuberkulin masih kontroversi. Namun respon uji tuberkulin dan pembentukkan parut BCG mungkin dapat menjadi pengganti yang lebih baik untuk memperkirakan efektifitas vaksin BCG yang tersedia saat ini.

Selama penelitian dilakukan tidak ditemukan efek samping pemberian vaksin BCG pada bayi BBLR yang menjadi subjek penelitian dan juga tidak ditemukan efek samping setelah dilakukan uji tuberkulin.

\section{Kesimpulan}

Pemberian vaksinasi BCG pada bayi BBLR dengan berat badan 2000 gram $-<2500$ gram, memberikan hasil yang tidak berbeda dengan bayi BBLR yang ditunda BCG nya sampai berat badan lebih atau sama 2500 gram. Parut BCG yang terbentuk juga tidak berbeda pada kedua kelompok bayi. Tidak ditemukan efek samping vaksinasi BCG dan uji tuberkulin selama penelitian ini dilakukan.

Peneliti menyarankan pemberian vaksinasi BCG pada bayi BBLR dapat dilakukan segera setelah lahir terutama pada bayi BBLR dengan berat badan 2000 gram sampai $\geq 2500$ gram, dan perlu dipertimbangkan untuk mengikutsertakan bayi BBLR dalam program imunisasi nasional BCG di Indonesia yang memiliki prevalensi tuberkulosis cukup tinggi.

\section{Daftar Pustaka}

1. Coulter B, Clinical review. Global epidemiology of tuberculosis. Paed Resp Med 1995; 2:12-15.

2. Inselsman LS. Tuberculosis in children: an update. Pediatr Pulmonol 1996; 21:101-20
3. Noerolandra. Pemberantasan TB terpadu di Indonesia: Beberapa kendala operasional. Medika 1999; 12:797805.

4. Nurul AH. Strategi penatalaksanaan TB menjelang millennium. Medika 1999; 12:805-8.

5. Rahajoe NN, Basir D, Makmuri MS, Kartasasmita CB, penyunting. Pedoman Nasional Tuberkulosis Anak. UKK Pulmonologi. Jakarta; Pengurus pusat IDAI; 2005. h. 75-6.

6. Kochi A. Leading article. The global tuberculosis situation and the new control strategy of the World Health Organization. Tubercle 1991; 71:1-6.

7. Aditama TY. Perkembangan mutakhir diagnosis tuberkulosis paru. Cermin Dunia Kedok 1995; 99:2931.

8. Hadinegoro SRS. Jadwal imunisasi rekomendasi IDAI. Dalam; Ranuh IGN, Suyitno H, Hadinegoro SRS, penyunting Pedoman imunisasi di Indonesia. Ed ke-2 tahun 2005. Jakarta: Satgas Imunisasi IDAI; 2005. h. 65-76.

9. Sudhan ST, Kumar A, Singh M. Safety and effectiveness of BCG vaccination in preterm babies. Arch Dis Child Fetal Neonatal Ed.1999; 81:64-66.

10. Baratawidjaja KG. Imunoprofilaksis. Dalam Baratawidjaja KG. Imunologi dasar. Edisi ke-3. Jakarta: Balai penerbit FKUI; 1996. h. 184-99.

11. Rodriques C, Diwan VK, Wheeler JK. Protective effect of BCG against tuberculous meningitis and military tuberculosis; a meta-analysis. International journal of epidemiology. 1998; 22:1154-8.

12. Dawodu AH. Tuberculin conversion following BCG vaccination in preterm infants. Acta Paediatr Scand 1985; 74:564-7.

13. Ferreira AA, Bunn-Moreno MM, Sant Anna CC, Ferreira MF. BCG vaccination in low birth weight newborns: analysis of lymphocyte proliferation IL-2 generation and intradermal reaction to PPD. Tuber Lung Dis 1996 ; 77:476-81.

14. Sedaghatian MR, Kardouni K. Tuberculin response in preterm infans after BCG vaccination at birth. Arch of Dis in Child 1993; 69:309-11.

15. Sedaghatian MR, Hashem F, Moshaddeque HM. Bacille Calmette Guerin vaccination in pre-term infants. Int J Tuberc Lung Dis 1998; 2:679-82.

16. Camargos P, Ribeiro Y, Teixeira A. Tuberculin skin reactivity after neonatal BCG vaccination in preterm infants in Minas Gerais, Brazil, 2001-2002. Rev Panam Salud Publica, 2006; 19:403-7. 